\title{
Trends and Factors Associated with Neonatal Sepsis at Ruhengeri Referral Hospital, Rwanda
}

\author{
Nimukuze $\mathrm{E}^{1,2}$, Mukarwego $\mathrm{B}^{1}$, Bizimana $\mathrm{GE}^{1,3}$ and \\ Rutayisire $\mathbf{E}^{1 *}$ \\ ${ }^{1}$ Department of Public Health, Mount Kenya University, \\ Rwanda \\ ${ }^{2}$ Department of Laboratory, Ruli District Hospital, \\ Rwanda Ministry of Health, Rwanda \\ ${ }^{3} \mathrm{~J}$ igsaw Consult/ Refugee Education, UK \\ *Corresponding author: Erigene Rutayisire, \\ Department of Public Health, Mount Kenya University, \\ Kigali, Rwanda
}

Received: J une 08, 2021; Accepted: July 07, 2021;

Published: July 14, 2021

\begin{abstract}
Neonatal sepsis is estimated to cause $26 \%$ of all neonatal mortality globally including Africa with $17 \%$ neonatal deaths. Early diagnosis and management can considerably decrease the risk of neonatal sepsis, and improve the outcome. This study aimed to determine trends and the risk factors associated with neonatal sepsis at Ruhengeri Referral Hospital from 2018 to 2019. A total of 1220 neonates' medical files were reviewed. Data were recorded and analyzed by using SPSS. Logistic regression analysis was used to estimate factors associated with neonatal sepsis, $5 \%$ was considered as significance level. Results showed that the majority of neonates $57.4 \%$ were females, $53.9 \%$ of neonates had 0-7 days while $46.1 \%$ had more than 7 days of birth. The total cases of neonatal sepsis from January to December 2018 were found to be 207 with an average of 17 cases per month whereas there were 165 cases from January to December 2019 with an average of 14 cases per month. Research findings revealed that rupture of membranes (AOR=3.6; $95 \% \mathrm{Cl}$ : $(1.34-4.76)$; $\mathrm{p}<0.001)$ and prolonged labour $(\mathrm{AOR}=1.5 ; 95 \% \mathrm{Cl}$ : $(1.12-2.43) ; \mathrm{p}<0.001)$ were associated with neonatal sepsis. Vaginal delivery and no history of urinary tract infection were protective factors to neonatal sepsis occurrence. The study also observed that the majority of the neonates had early onset of sepsis ( $<7$ days). Hence, encouraging mothers to use antenatal care services might help identify the risk factors and possible interventions to reduce the risk factors of adverse birth outcomes including neonatal sepsis.
\end{abstract}

Keywords: Neonatal sepsis; Neonatal death; Ruhengeli referral hospital

\section{Introduction}

Sepsis is a dysregulated host response to infection leading to lifethreatening organ dysfunction [1]. The Global Burden of Disease (GBD) estimated 1.3 million annual incident cases of neonatal sepsis and other infections (approximately 937 cases per 100000 live births) and 203000 sepsis-attributable neonatal deaths [2,3].

Neonates are disproportionately affected in Low-Income and Middle-Income Countries (LMICs) with a high prevalence of infectious diseases and poor access to adequately equipped and staffed healthcare facilities [4,5]. In sub-Saharan Africa alone, an estimated 5.3-8.7 million disability-adjusted life-years have been lost in 2014 due to neonatal sepsis and consecutive long-term morbidity [6]. In sub-Saharan Africa neonatal sepsis is the main newborn killer where more than one third of neonatal deaths [7].

Neonatal sepsis is categorized based on the time of occurrence including early onset diseases (EOD) and late onset diseases (LOD). This differentiation has clinical fact: for instance, EOD is mostly caused by bacteria attracted before and during birth whereas LOD bacteria are attracted afterbirth from health facility or community [8]. Early onset of sepsis remains a common and big issue for neonate, especially intrapartum antimicrobial streptococcus (BGS) commonly found to be an etiological agent, but Escherichia viral or fungal etiology may also manifested at 7 days of life and must be differentiated from bacteria sepsis [9].

In Rwanda, there has been a significant decrease in under-five mortality, from 196 per 1000 live births in 2000 to 50 per 1000 live birth in 2015, making the country one of the dew in SSA to achieve the MDGs for child mortality. Again, the neonatal mortality rate significantly decreased from 41 per 1000 live births in 1990 to 17 per 1000 live births in 2016 [10]. The main cause of neonatal mortality in Rwanda are prematurity (41\%), and neonatal sepsis (10\%) [11]. The Rwanda Demographic Health Survey (RDHS 2014-2015) reported that newborn death was 20/1000 live birth [12].

To our knowledge no study have been conducted in Northern Province of Rwanda assessed the risk factors of neonatal sepsis. A report from Ruhengeri hospital showed that 2142 neonates admitted in neonatology in 2016 of them 514 (24\%) were reported to have neonatal infections during hospitalization. Therefore, this research sought to assess the trends and factors associated with neonatal sepsis in Rwanda with special focus on Ruhengeri Referral Hospital.

\section{Materials and Methods}

\section{Study design}

This research was a descriptive hospital-based retrospective study. This study has used quantitative approach to determine the trends, and factors associated with neonatal sepsis among hospitalized neonates. This study was conducted among neonates hospitalized in neonatal unit at Ruhengeri Referral Hospital located in Northern Province, Musanze District of Rwanda. Ruhengeri referral hospital serves 413,470 people with 17 health centers. The hospital building comprises the pediatric department with 96 beds among them 36 beds
Austin J Womens Health - Volume 8 Issue 3 - 2021

Submit your Manuscript | www.austinpublishing group.com

Rutayisire et al. (C) All rights are reserved
Citation: Nimukuze E, Mukarwego B, Bizimana GE and Rutayisire E. Trends and Factors Associated with Neonatal Sepsis at Ruhengeri Referral Hospital, Rwanda. Austin J Womens Health. 2021; 8(3): 1055 
and 11 incubators and 12 staffs among them 3 health care providers are on daily shift in neonatal unit.

\section{Target population}

The study targeted 1220 individuals composed with neonates and mothers found in neonatal unit from January 2018 to December 2019. All 1220 medical records (neonates' files) from Neonatal units with inclusion criteria were checked during data collection period from January 1, 2018 to December 31, 2019.

A structured checklist was used to retrieve needed information from neonate's medical files. Mainly, the checklist comprised the socio-demographic features, maternal and pregnancy- related factors and neonates-related factors.

\section{Data analysis and ethical consideration}

Data collected was analyzed by using SPSS after being coded, compiled and recorded. Descriptive statistics showing frequency distributions and percentage have been used to represent variables under study. Research findings are presented in tables and graphs. Multivariate analysis was used to determine statistical associations between the dependent and independent variables. A two tailed p-value of less than or equal to 0.05 at $95 \%$ confidence interval has been used in order to state the statistical significance.

This study was approved by Mount Kenya University Rwanda Ethical review board. The ethical approval was presented to the Ruhengeri Referral Hospital Administration to obtain permission to carry out the study according to the required rules and regulations of hospital administration. The hospital management's team was informed that findings are to be used for academic purpose and confidentiality was ensured.

\section{Results}

A total of 1220 clients' files have been reviewed in line with the objectives and giving a response rate of $100 \%$.

\section{Socio-demographic characteristics of the mothers}

As presented in table 1, a total of 1220 medical files equals to a total of 1220 mothers aged at least 18years old have been reviewed in the Neonatal Unit at Ruhengeri Referral Hospital. Findings revealed that $66.2 \%$ of mothers were aged between 18 and 35 years, $57.1 \%$ were in the second social category, $66.7 \%$ were coming from rural areas, most of the mothers (75.3\%) had attended primary school, a big part of the mothers $(76.0 \%)$ were married while the majority of the mothers (73.4\%) of the mothers were unemployed.

\section{Trends of neonatal sepsis at Ruhengeri Referral Hospital}

The trends of neonatal sepsis among neonates hospitalized in neonatal unit at Ruhengeri Referral Hospital between 2018 and 2019 are shown in Figure 1.

The total cases of neonatal sepsis from January to December 2018 were found to be 207 cases with an average of 17 cases per month whereas there were 165 cases from January to December 2019 with an average of 14 cases per month. These findings show a decrease in neonatal sepsis cases from 2018 to 2019. Findings in Figure 1 indicate that there was an increase of neonatal sepsis in the February 2018 (from 15 cases to 23 cases) whereas it has decreased in February 2019 (from 18 cases to 13 cases). A high increase of cases was observed

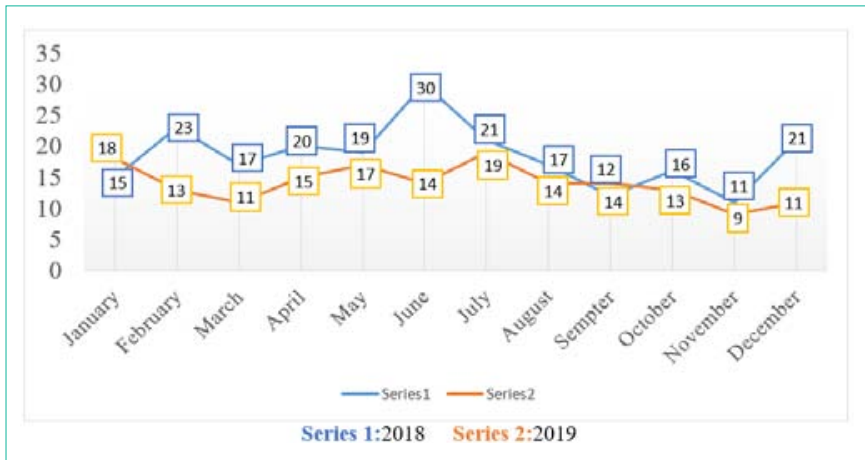

Figure 1: Trends of neonatal sepsis between 2018 and 2019.

Table 1: Socio-demographic characteristics of the mothers.

\begin{tabular}{|c|c|c|c|}
\hline Variables & Items & Frequency (n) & Percent (\%) \\
\hline \multirow{2}{*}{ Mother's age } & 18-35 years & 808 & 66.2 \\
\hline & More than 35 years & 412 & 33.8 \\
\hline \multirow{4}{*}{$\begin{array}{c}\text { Social category } \\
\text { [Ubudehe] }\end{array}$} & Category 1 & 184 & 15.1 \\
\hline & Category 2 & 697 & 57.1 \\
\hline & Category 3 & 316 & 25.9 \\
\hline & Category 4 & 23 & 1.9 \\
\hline \multirow{2}{*}{ Residence } & Rural & 814 & 66.7 \\
\hline & Urban & 406 & 33.3 \\
\hline \multirow{3}{*}{ Education level } & Primary education & 919 & 75.3 \\
\hline & Secondary school & 173 & 14.2 \\
\hline & University & 128 & 10.5 \\
\hline \multirow{4}{*}{ Marital status } & Single & 217 & 17.8 \\
\hline & Married & 927 & 76 \\
\hline & Divorced & 53 & 4.3 \\
\hline & Widowed & 23 & 1.9 \\
\hline \multirow{2}{*}{ Employment status } & Employed & 325 & 26.6 \\
\hline & Unemployed & 895 & 73.4 \\
\hline
\end{tabular}

from May to June 2018 (from 19 cases to 30 cases); while there was a decrease from May to June 2019 (from 17 cases to 14 cases). At the end the year, the number of cases of neonatal sepsis has re-increased for both 2018 and 2019 from 11 cases to 21 cases and from 9 to 11 cases respectively.

Findings show that $30.3 \%$ of neonates hospitalized in neonatal unit at Ruhengeri Referral Hospital from 2018 and 2019 had neonatal sepsis.

\section{Factors associated with sepsis at Ruhengeri Hospital}

The findings revealed that neonates aged above 23 days were less likely to have sepsis than neonates aged $\leq 7$ days $(\mathrm{AOR}=0.6 ; 95 \% \mathrm{CI}$ : [0.25-0.96]; $\mathrm{p}=0.043)$; neonates without congenital malformations were less likely to have neonatal sepsis than those with congenital malformations (AOR $=0.3$; 95\% CI: (0.06-3.43); $\mathrm{p}=0.002)$. Mother's without diseases history during their pregnancies were less likely to have children with neonatal sepsis than women suffered from any disease during pregnancies ( $\mathrm{AOR}=0.4$; 95\% CI: (0.25-0.86); $\mathrm{p}=0.002$ ); women with no history of urinary tract infections during pregnancy were less likely to have children with neonatal sepsis than women 
Table 2: Predictors of neonatal sepsis among hospitalized neonates at RRH.

\begin{tabular}{|c|c|c|c|c|}
\hline Characteristics & Items & Crude OR (95\% Cl) & Adjusted OR $(95 \% \mathrm{Cl})$ & p-value \\
\hline \multirow{2}{*}{ Mother's age } & 18-35 years & Ref. & Ref. & Ref. \\
\hline & More than 35 years & $1.3(1.05-1.79)$ & $0.5(0.15-2.24)$ & 0.715 \\
\hline \multirow{4}{*}{ Mother's social category [Ubudehe] } & Category 1 & Ref. & Ref. & Ref. \\
\hline & Category 2 & $3.1(2.22-4.37)$ & $1.9(0.50-4.98)$ & 0.624 \\
\hline & Category 3 & $1.5(1.07-2.24)$ & $1.3(0.41-3.35)$ & 0.415 \\
\hline & Category 4 & $2.06(2.72-15.6)$ & $1.1(0.42-2.53)$ & 0.112 \\
\hline \multirow{3}{*}{ Mother's education level } & Primary education & Ref. & Ref. & Ref. \\
\hline & Secondary school & $1.7(1.23-2.58)$ & $0.8(0.25-1.44)$ & 0.082 \\
\hline & University & $0.9(0.59-1.46)$ & $0.7(0.21-2.14)$ & 0.754 \\
\hline \multirow{2}{*}{ Mother's employment status } & Employed & Ref. & Ref. & Ref. \\
\hline & Unemployed & $0.6(0.47-0.85)$ & $0.4(0.15-1.74)$ & 0.463 \\
\hline \multirow{4}{*}{ Neonate's age } & 0-7 days & Ref. & Ref. & Ref. \\
\hline & 8-15 days & $1.4(1.12-1.95)$ & $0.12(0.07-0.93)$ & 0.089 \\
\hline & $16-23$ days & $1.03(0.61-2.5)$ & $0.4(0.07-1.99)$ & 0.067 \\
\hline & Above 23 days & $0.7(0.47-1.19$ & $0.6(0.25-0.96)$ & 0.043 \\
\hline \multirow{2}{*}{ Neonate's gender } & Male & Ref. & Ref. & Ref. \\
\hline & Female & $0.7(0.60-0.99)$ & $1.1(0.31-1.37)$ & 0.226 \\
\hline \multirow{2}{*}{ Congenital malformations } & Yes & Ref. & Ref. & Ref. \\
\hline & No & $0.4(0.25-0.73$ & $0.3(0.06-3.43)$ & 0.002 \\
\hline \multirow{2}{*}{ Diseases during pregnancy } & Yes & Ref. & Ref. & Ref. \\
\hline & No & $1.5(1.14-1.87)$ & $0.4(0.25-0.86)$ & 0.002 \\
\hline \multirow{2}{*}{ Urinary tract infections } & Yes & Ref. & Ref. & Ref. \\
\hline & No & $0.3(0.27-0.48)$ & $0.2(0.12-0.81)$ & $<0.001$ \\
\hline \multirow{2}{*}{ Mode of delivery } & C-section & Ref. & Ref. & Ref. \\
\hline & Vaginal & $0.7(0.58-0.96)$ & $0.3(0.013-0.819)$ & 0.025 \\
\hline \multirow{2}{*}{ Birth attended by skilled personnel } & Yes & Ref. & Ref. & Ref. \\
\hline & No & $3.02(1.81-5.06$ & $2.1(1.43-4.35)$ & $<0.001$ \\
\hline \multirow{2}{*}{ Rupture of membranes } & Yes & $3.8(1.24-5.63)$ & $3.6(1.34-4.76)$ & $<0.001$ \\
\hline & No & Ref. & Ref. & Ref. \\
\hline \multirow{2}{*}{ Prolonged labour } & Yes & $1.9(1.41-2.77)$ & $1.5(1.12-2.43)$ & $<0.001$ \\
\hline & No & Ref. & Ref. & Ref. \\
\hline
\end{tabular}

with history of urinary tract infections $(\mathrm{AOR}=0.2 ; 95 \% \mathrm{CI}$ : $(0.12$ $0.81) ; \mathrm{p}<0.001)$; Neonates born vaginally were less likely to have neonatal sepsis than neonates delivered by $\mathrm{C}$-section (AOR=0.3; $95 \%$ CI: (0.013-0.819); $\mathrm{p}=0.025)$; the odds of having neonatal sepsis was 2.1 times higher among births not attended by a skilled personnel than births attended by skilled personnel (AOR=2.1; 95\% CI: (1.434.35); $\mathrm{p}<0.001)$; mothers with rupture of membranes were more likely (AOR=3.6; 95\% CI: (1.34-4.76); $\mathrm{p}<0.001)$ and mothers experienced prolonged labor were 1.5 times more likely delivering children with neonatal sepsis than those who did not experience it $(\mathrm{AOR}=1.5 ; 95 \%$ CI: (1.12-2.43); $\mathrm{p}<0.001)$.

\section{Discussion}

The present study assessed factors associated with neonatal sepsis at Ruhengeri Referral Hospital in Rwanda in order to tackle the disease burden and its specific associated problems.
The study has documented the trends and factors associated with neonatal sepsis among 1220 hospitalized neonatesin the study area. Neonatal sepsis is the most common diagnosis in neonatal intensive care units [13-15].

Research findings revealed that there was an increase of neonatal sepsis in January 2018 with 23 cases of neonatal sepsis whereas it has decreased in January 2019 with 13 cases of neonatal sepsis. Forthcoming the mid-year (June) 2018 and 2019, the number of neonatal sepsis cases highly increased from 19 cases on May 1, 2018 to 30 cases on June 1, 2018 while there was a decrease in the same months of 2019 (from 17 cases on May 1, 2019 to 14 cases on June $1,2019)$. The study findings have shown different findings with the previous findings from Iran and Korea $[16,17]$.

The decrease of the rate of neonatal sepsis found in this study, difference in studies conducted Iran, and Korea may be attributed to 
the efforts made by Rwanda Ministry of Health and its partners who availed disease prevention guidelines and tools in all health facilities of Rwanda including Ruhengeri Referral Hospital.

In this study, the prevalence of neonatal sepsis was found to be $30.3 \%$ with about $34.7 \%$ of these cases with early-onset neonatal sepsis ( $<7$ days), which is to ascertain extent comparable with other studies $[18,19]$.

Many studies conducted around the world display differently the prevalence of neonatal sepsis; however, the prevalence of studies done around Sub Saharan Africa and other developing countries is higher than that of the developed countries [20]. The prevalence in our study is comparable with studies from different sides of the world: $37.6 \%$ in North-West Nigeria [21], 39\% in New Delhi, India [22], 45.9\% in Egypt [23] 38.9\% at a tertiary hospital in Mwanza, Tanzania [24] and 31.4\% in Dar Es Salam, Tanzania [25].

Similar findings were as well obtained in a study conducted Nigerian Teaching hospitals that reported a neonatal sepsis prevalence of $33.1 \%$ [26]. A prevalence of $38.9 \%$ was found in a study conducted in Benin City, Nigeria [27], 42\% in University of Maiduguri Teaching Hospital [28], 41.2\% in Jos University Teaching Hospital [29], and $35.5 \%$ in ABUTH University Teaching hospital, Zaria, Nigeria [30]. The reasons for these disparities could be referred to the difference in hospital settings as it has been shown that neonatal sepsis is an issue in resource-poor settings [31].

The current study findings revealed that the odds that a neonate develops sepsis decreased with an increasing in neonatal age. Those findings contrasted with findings from a study conducted in Ghana where the probability that a neonate develops sepsis increased with increasing neonatal age ( $<7$ days) [32]. Furthermore, those findings from Ghana were consistent with the study conducted in Ethiopia [7]

In this study, neonates born to mothers who had not got urinary tract infections (UTI) during pregnancy were less likely to have sepsis. This finding is equivalent with the findings of previous studies conducted in Ghana and Ethiopia $[7,33]$. These findings were consistent with the statement that maternal UTI is often associated with early-onset neonatal sepsis, especially if untreated during the third-trimester pregnancy or labor, and it may be associated with neonatal sepsis following the colonization of the birth canal by the infectious agent [34].

In the line with the present findings, a study conducted in Indonesia, Utomo found cesarean section is risk of developing neonatal sepsis, which is inconsistent with the results of the current study [35]. It is noted that newborns delivered through the normal way (vaginal) have been found less likely to have neonatal sepsis than those born through $\mathrm{C}$-section even if they are exposed to vaginal and fecal bacteria $[36,37]$.

In this study, early rupture of membranes and prolonged labor has found to increase the odds of ascending microorganisms from the birth canal into the amniotic sac and fetal compromise as well as asphyxia, which frequently leads to sepsis in the neonatal period. This finding was consistent with findings from a study conducted by Endale et al. where neonates born to mothers who had premature rupture of membranes during pregnancy were 4.6 times more likely to have developed sepsis [38] These findings could serve as justification for prophylactic antibiotic therapy for neonates born to mothers with a history of premature rupture of membranes during pregnancy. Furthermore, several other study findings $[37,39,40]$ were found to be inconsistent with the current study findings.

\section{Conclusion}

In this study, the trend of neonatal sepsis at Ruhengeri Referral Hospital has found to vary month per month during the study period. The prevalence of neonatal sepsis was found to be high among the neonates studied. Most important significant maternal and neonatal predictors to neonatal sepsis were found to be neonate's age, diseases during pregnancies, urinary tract infections, delivery mode, who attended the birth, rupture of membranes and prolonged labor. Therefore, encouraging mothers to use antenatal care services might help identify the risk factors and possible interventions to reduce the risk factors of adverse birth outcomes including neonatal sepsis. And also healthcare personnel improving the care they render to mothers and babies could be a key factor in reducing neonatal sepsis. There is a need to effectively plan and implement the neonatal sepsis education and promotion sessions targeting mothers and health care providers.

\section{References}

1. Singer M, Deutschman CS, Seymour CW, et al. The third International consensus definitions for sepsis and septic shock (Sepsis-3). JAMA. 2016; 315: 801-810.

2. GBD 2017 Disease and Injury Incidence and Prevalence Collaborators. Global, regional, and national incidence, prevalence, and years lived with disability for 354 diseases and injuries for 195 countries and territories, 1990 2017: a systematic analysis for the global burden of disease study 2017. Lancet. 2018; 392: 1789-1858.

3. GBD 2017 Causes of Death Collaborators. Global, regional, and nationa age-sex-specific mortality for 282 causes of death in 195 countries and territories, 1980-2017: a systematic analysis for the global burden of disease study 2017. Lancet. 2018; 392: 1736-1788.

4. GBD 2013 Mortality and Causes of Death Collaborators. Global, regional, and national age-sex specific all-cause and cause-specific mortality for 240 causes of death, 1990-2013: a systematic analysis for the global burden of disease study 2013. Lancet. 2015; 385: 117-171.

5. Nwankwor OC, McKelvie B, Frizzola M, et al. A national survey of resources to address sepsis in children in tertiary care centers in Nigeria. Front Pediatr. 2019; $7: 234$.

6. Ranjeva SL, Warf BC, Schiff SJ. Economic burden of neonatal sepsis in subSaharan Africa. BMJ Glob Health. 2018; 3: e000347.

7. Gebremedhin et al. Risk factors for neonatal sepsis in public hospitals of Mekelle City, North Ethiopia, 2015: Unmatched case control study. PLoS ONE. 2016; 11: e0154798.

8. Nathan S. Neonatal Sepsis. Medscape. 2019.

9. Simonsen AAK, Anderson-Berry A, Shirley F, Dlair H \& Dele D. Early-Onset Neonatal Sepsis. Clinical Microbiology Reviews. 2014.

10. UNICEF. Child survival and the SDGs. Retrieved from looking ahead: Child survival and the Sustainable Development Goals. 2020.

11. $\mathrm{MOH}$ [Rwanda]. Maternal Newborn and Child Health Strategic Plan (20182024). Kigali: Ministry of Health [Rwanda]. 2018.

12. NISR, MOH \& ICF. Rwanda Demographic and Health Survey 2014-15. Rockville, Maryland, USA: National Institute of Statistics of Rwanda (NISR), Ministry of Health (MOH) [Rwanda] \& ICF International. 2015.

13. Vergnano et al. Characteristics of invasive Staphylococcus aureus in United Kingdom neonatal units. Pediatr Infect Dis J. 2011; 30: 850-854. 
14. Camacho-Gonzalez A, Spearman P \& Stoll B. Neonatal infectious diseases: evaluation of neonatal sepsis. Pediatr Clin North Am. 2013; 60: 367-389.

15. Clark et al. Reported medication use in the neonatal intensive care unit: data from a large national data set. Pediatrics. 2016; 117: 1979-1987.

16. Shin $Y$ \& Foxman B. Epidemiology of neonatal sepsis in South Korea. Pediatr Int. 2019; 51: 225-232.

17. Khalili, et al. Evaluation of the most common clinical signs and laboratory findings of neonatal sepsis in in Baqyatallah and Najmie Hospitals from 1380 to 1384 . Journal of Military Medicine. 2017; 9: 233-240.

18. Gebrehiwot A, Lakew W, Moges F, Moges B, Anagaw B \& Unakal C. Predictors of positive blood culture and death among neonates with suspected neonatal sepsis in Gondar University Hospital, Northwest Ethiopia. European Journal of Experimental Biology. 2012; 2: 2212-2218.

19. Woldu M, Guta M, Lenjisa J, Tegegne G, Tesafye G \& Dinsa H. Assessment of the Incidence of Neonatal Sepsis, its Risk Factors, Antimicrobials Use and Clinical Outcomes in Bishoftu General Hospital, Neonatal Intensive Care Unit, Debrezeit-Ethiopia. Pediatrics \& Therapeutics. 2014; 4: 214.

20. Vergnano S, Sharland M, Kazembe P, Mharland S, Mwansambo C \& Heath P. Neonatal sepsis: An international perspective. Arch Dis Child Fetal Neonatal. 2015; 90: F220-224.

21. Abdulhakeem A, Williams RI, Muhammed SI, Muhammad BJ, Lawal A \& Bola BL. Prevalence and Factors Associated with Neonatal Sepsis in a Tertiary Hospital, North West Nigeria. Niger Med J. 2020; 61: 60-66.

22. Jajoo M, Kapoor K, Garg L, Attal B, Manchanda V \& Mittal S. To study the incidence and risk factors of early onset neonatal sepsis in an out born neonatal intensive care unit of India. J Clin Neonatol. 2015; 4: 91.

23. Shehab E, Shehab ME, EISokkary M, Bassiouny M, Bassiouny R \& Hassan R. Epidemiology of neonatal sepsis and implicated pathogens: A study from Egypt. Biomed Res Int. 2015: 509484.

24. Kayange N, Kamugisha E, Mwizamholya D, Mwiza L, Jeremiah S \& Mshana S. Predictors of positive blood culture and deaths among neonates with suspected neonatal sepsis in a tertiary hospital, Mwanza-Tanzania. BMC Pediatr. 2010; 10: 39

25. Jabiri A, Wella HL, Semiono A, Sariah A, Protas J \& Wella L. Prevalence and factors associated with neonatal sepsis among neonates in Temeke and Mwananyamala Hospitals in Dar es Salaam, Tanzania. African Journa Online. 2016; 18: 1-7.

26. Ogunlesi T \& Ogunfowora O. Predictors of mortality in neonatal septicemia in an underresourced setting. J Natl Med Assoc. 2010; 102: 915-921.

27. Omoregie R, Egbe C, Dagba A, Dirisu J, Ogefere H \& Ogefere O. Microbiology of neonatal septicemia in a tertiary hospital in Benin City, Nigeria. Biomarkers Genomic Med. 2013; 5: 142-146.
28. Pius S, Bello M, Galadima G, Ibrahim H, Yerima S \& Ambe J. Neonatal septicaemia, bacterial isolates and antibiogram sensitivity in Maiduguri NorthEastern Nigeria. Niger Postgrad Med J. 2016; 23: 146-151.

29. Onyedibe K, Okolo O, Toma B, Onyedibe I, Afolaranmi TA \& Okolo M. The necessity of full sepsis screen in neonatal sepsis: Experience in a resourcelimited setting. Sahel Med J. 2016; 19: 89-93.

30. Onalo R, Ogala W, Ogunrinde G, Olayinka A, Adama S \& Ega B. Predisposing factors to neonatal septicaemia at ahmadu bello University teaching hospital, Zaria Nigeria. Niger Postgrad Med J. 2011; 18: 20-25.

31. Rahman A, Iqbal A, Hoque D, Moinuddin M, Zaman S \& Rahman $Q$. Managing neonatal and early childhood syndromic sepsis in sub-district hospitals in resource poor settings: Improvement in quality of care through introduction of a package of interventions in rural Bangladesh. PLoS One. 2017; 12: e0170267.

32. Adatara P, Agani A, Solomon M, Richard A, Kennedy D, Eric A-F, et al. Risk Factors Associated with Neonatal Sepsis: A Case Study at a Specialist Hospital in Ghana. The Scientific World Journal. 2019; 2019: 9369051

33. Siakwa M, Kpikpitse D, Mupepi S, Semuatu M, Soraya H \& Dumos K. Neonatal sepsis in rural Ghana: A case control study of risk factors in a birth cohort. International Journal of research In Medical and Health Science. 2014; 4: 77-88

34. Akindolire A, Tongo O, Adebay K, Tadja M, Dada-Adegbola H \& Akinyinka O. Etiology of early onset septicemia among neonates at the University college hospital, Ibadan, Nigeria. J Infect Dev Ctries. 2016; 10: 1338-1344.

35. Utomo M. Risk Factors of Neonatal Sepsis: A Preliminary Study in Dr Soetomo Hospital. Indonesian Journal of Tropical and Infectious Disease. 2016; 1: 23-26

36. Bager $\mathrm{P} \&$ Simonsen J. Cesarean delivery and risk of intestinal bacteria infection. The Journal of Infectious Diseases. 2010; 201: 898-902.

37. Rowe-Murray HJ \& Fisher JR. Baby Friendly Hospital practices: Cesarean section is a persistent barrier to early initiation of breastfeeding. Women and Birth. 2016; 29: 124-131.

38. Endale T, Hussen M, Fentahun N, Fatima K, Gemada D, Hussen A, et al Maternal and fetal outcomes in term premature rupture of membrane. World J Emerg Med. 2016; 7: 147-152.

39. Hasan M \& Mahmood C. Predictive Values of Risk Factors in Neonatal Sepsis. Journal of Bangladesh College of Physicians and Surgeons. 2011 29: 187-195.

40. Mugadza G, Zvinavashe M, Gumbo F, Pedersen B, Gumbo Z \& Pedersen $S$. Early breastfeeding initiation and incidence of neonatal sepsis in Chipinge District Zimbabwe. International Journal of Contemporary Pediatrics. 2018; 5: $1-5$ 